\title{
Diabetes Mellitus Therapy
}

\author{
Ahmed M Abu-Dief* \\ Chemistry Department, Faculty of Science, Sohag University, Egypt
}

Received: April 12, 2018; Published: April 19, 2018

*Corresponding author: Ahmed M Abu-Dief, Chemistry Department, Faculty of Science, Sohag University-82524, Egypt, Email: ahmed_benzoic@yahho.com

\section{Introduction}

Diabetes is depicted by hyperglycemia, altered lipids, carbohydrates, and proteins metabolism which affect the patient nature of life in terms of social, psychological well- being as well as physical ill health [1,2]. Two forms of diabetes (Types 1 and 2) differ in their pathogenesis, but both have hyperglycemia as a common hall mark. In type 2 diabetes, hyperglycemia caused due to deterioration in insulin secretion combined with or without impairment of insulin action [3]. The World Health Organization declared that worldwide global population is in the midst of a diabetes epidemic. The people in Southeast Asia and Western Pacific are being under greater risk, and the majority of patients have type 2 diabetes. Insulin impedance typically precedes the onset of type 2 diabetes and is commonly accompanied by other cardiovascular risk factors such as dyslipidemia, hypertension, and prothrombotic factors [4]. Diabetes mellitus (DM), a leading non removable disease with multiple etiologies, is deemed as one of the five leading causes of death in the world. The total number of people with diabetes is projected to rise from 171 million in 2000 to 366 million in 2030 [5].

DM is a clinically and genetically heterogeneous group of disorders, characterized by abnormally high blood glucose concentration. Several pathogenic processes are interested in the development of diabetes. These range from autoimmune destruction of the $\beta$-cells of the pancreas from inadequate insulin secretion and/or reduce tissue restraints to insulin at one or more points in the complex pathways of hormone action. Insufficient supply of insulin cause abnormalities in carbohydrate, fat, and protein metabolism. These metabolic disturbances result in acute and long term diabetic complications, which are responsible for premature death and disability [6]. In order to inhibit the onset of such entanglement, tight control of fasting and postprandial blood glucose levels is a central aspect of diabetes treatment. It has been mentioned that medicinal plants may provide valuable therapeutics agents in modern medicine and in traditional system, especially in areaswhere the modern drugs are unavailable [7]. Though there are plentiful medicinal plants traditionally reported to have hypoglycemic feature. Many of them confirmed to be not effective in depreciation glucose levels in serious diabetes and notified to have side effects including metabolic coma, hematological troubles, and disturbances of kidney and liver. Subsequently, there is a necessity to search for more effective and safe drugs for diabetes [8]. Accomplishment new therapies that can administer glucose level are of major importance in recent directions. Metallotherapy is an increasing area of interest in the remediation of diabetes mellitus. Coordination compounds proposed to have the capacity to excavate beneficial effect in the pathogenesis and complication of the disease.

The concept of using metal ions for the remediation of diabetes generates from the report in 1899. A number of transitional and coordination compounds such as vanadium, chromium, manganese,cobalt, copper, zinc, tungsten and molybdenum have been suggested as possible adjuncts in the remediation of diabetes mellitus in vivoandin vitro $[9,10]$. Metal compounds induce hypoglycemia by a wide diversity of mechanisms. Potential mechanisms of their antidiabetic insulin-like effects are activation of insulin receptor transmission (magnesium, chromium), inhibition of phosphatases (vanadium), antioxidant properties (tungstate, cobalt, manganese, zinc), lipid synthesis in muscle glycogen and excitation of glucose absorption, fleshy and hepatic tissues and suppressionof gluconeogenesis (chromium, cobalt) or energizing of the activities of the gluconeogenic enzymes: glucose-6 phosphatase (manganese) and phosphoenol pyruvate carboxykinase [11,12]. Chromium, vanadium, zinc, copper, cobalt, and tungsten were found to be efficacious for treating diabetes in experimental animals. But still a long time use of the coordination compounds as hypoglycemic drugs has to be estimated in order to have a safety and profitable effect.

\section{References}

1. Davis S (2006) Insulin, oral hypoglycemic agents and the pharmacology of the endocrine pancreas. In: L Brunton, J Lazo, K Parker. editors. The Pharmacological Basis of Therapeutics. New York: McGraw-Hill 1613.

2. Dewanjee S, Das AK, Sahu R, Gangopadhyay M (2009) Antidiabetic activity of Diospyrosperegrina fruit: effect on hyperglycemia, 
hyperlipidemia and augmented oxidative stress in experimental type 2 diabetes. Food and Chemical Toxicology 47(10): 2679-2685.

3. Lin Y, Sun Z (2010) Current views on type 2 diabetes. Journal of Endocrinology 204(1): 1-11.

4. Gray RS, Fabsitz RR, Cowan LD, Lee ET, Howard BV, et al. (1998) Risk factor clustering in the insulin resistance syndrome. The strong heart study. American Journal of Epidemiology. Chemistry Reviews 148(9): 969-878.

5. Wild S, Roglic K, Green A, Sicree R, King H (2004) Global prevalence of diabetes. Estimation for the year 2000 and projections for 2030. Diabetes Care 27: 1047-1053.

6. (2004) Diagnosis and classification of diabetes mellitus. ADA. Diabetes Care 27(1): S5-S10.

7. (1994) Prevention of diabetes mellitus. Technical Report Series WHO. Geneva pp. 844-848.
8. Pari L, Uma MJ (1999) Hypo-glycemic effect of Musa sapientum L. in alloxan-induced diabetic rats. J Ethnopharmaco 68(1-3): 321-325.

9. Bharti SK, Singh SK (2009) Metal Based Drugs: Current Use and Future Potential Der Pharmacia. Lettre 1: 39-51.

10. Rafique S, Idrees M, Nasim A, Akbar H, Athar A (2010) Transition metal complexes as potential therapeutic agents. Biotech Mol Biol Rev 5(2): 38-45.

11. Wiernsperger N, Rapin JR (2010) Trace elements in glucometabolic disorders: an update. Diabetol Metabol Syn 2: 70.

12. Sakurai H, Katoh A, Kiss T, Jakusch T, Hattori M (2010) Metallo-allixinate complexes with anti-diabetic and anti-metabolic syndrome activities. Metallomics 2(10): 670-682.

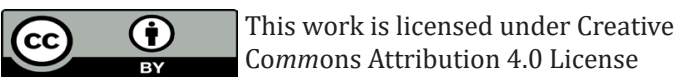

Submission Link: https://biomedres.us/submit-manuscript.php

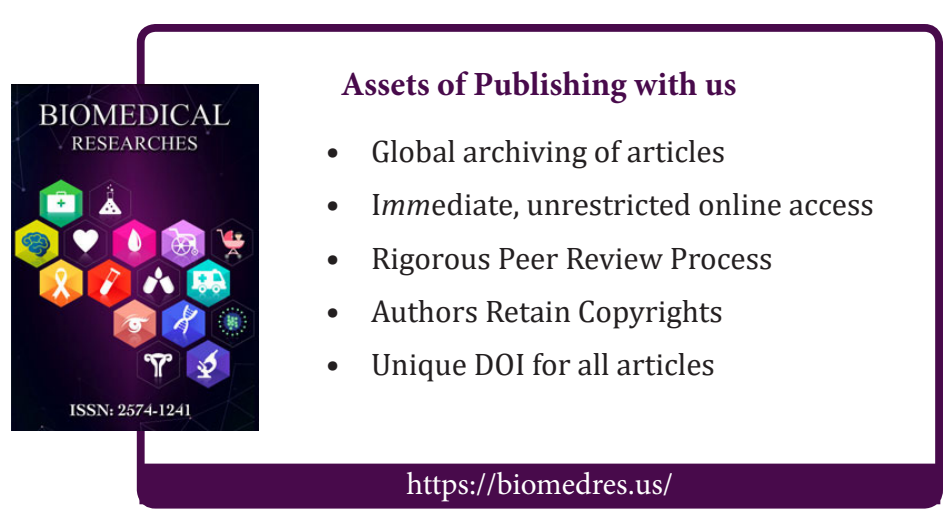

